\title{
Strongyloides stercoralis en el sur de Galicia
}

\author{
C. MARTÍNEZ-VÁZQUEZ, G.GONZÁLEZ MEDIERO', M. NÚÑEZ, S. PÉREZ, \\ J.M. GARCÍA-FERNÁNDEZ, B.GIMENA
}

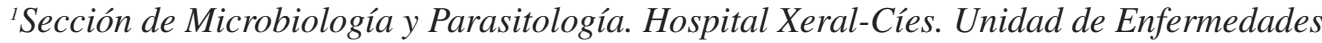
Infecciosas. Universidad de Santiago. Vigo

STRONGYLOIDES STERCORALIS IN THE SOUTH OF GALICIA (SPAIN)

\section{RESUMEN}

Strongyloides stercoralis es el único parásito que puede producir enfermedad crónica en el ser humano perpetuándose por autoinfección. Este nematodo, además, puede condicionar la muerte cuando se deteriora el estado inmunológico de paciente produciéndo una hiperinfección masiva.

Se describe el primer paciente afecto de strongiloidiasis siempre residente en el área sur de Galicia. El cuadro clínico cursó con lesiones cutáneas inespecíficas y dolor abdominal con intensa eosinofilia periférica $(>20.000 / \mathrm{ml})$. El diagnóstico se realizó mediante la objetivación de larvas en heces, confirmada mediante cultivo. El tratamiento con albendazol fracasó, consiguiéndose la curación mediante ivermectina.

Debemos aumentar nuestro índice de sospecha sobre todo por la posibilidad de diagnosticar a estos pacientes como gastroenteritis eosinofílica, con el riesgo de "hiperinfección" que conllevaría el tratamiento con cortisona.

PALABRAS CLAVE: Strongyloides stercoralis. Hiperinfección. Gastroenteritis eosinofílica.
ABSTRACT

Strongyloides stercoralis is the only parasite which can produce a chronic illness in humans, being through autoinfection. This nematode can also provoke death when patient's immunologic state deteriorates producing a massive hyper infection.

The first patient with strongyloidiasis who has always lived in the Galician South area is described. The clinical picture consisted of unspecific cutaneous lesions and abdominal pain with severe peripheral eosinophilia (>20.000/ml. The diagnosis was carried out observing the larvae in the fecal examination and was confirmed with a culture. Treatment with albendazole failed and the healing was reached with ivermectin. We must consider the possibility of strongyloidiasis because misdiagnosing these patients as eosinophilic gastroenteritis there would be a higher risk of hyperinfection if they are treated with corticosteroids

KEY WORDS: Strongyloides stercoralis. Hiperinfection. Eosinophilic gastroenteritis .

Martínez-Vázquez, C, González, Mediero G, Núñez, M, Pérez, S, García-Fernández, JM, Gimena B. Strongyloides stercoralis en el sur de Galicia. An Med Interna (Madrid) 2003; 20: 477-479.

\section{INTRODUCCIÓN}

Strongyloides stercoralis es un parásito perteneciente al grupo de los nematodos, endémico en regiones rurales de países con clima tropical y subtropical en donde puede afectar entre $30 \mathrm{y}$ 100 millones de personas (1,2). En España se han descrito casos principalmente a lo largo de la costa mediterránea en la zona de Salor (Valencia) en relación con labores agrícolas (3).

$\mathrm{Su}$ importancia radica en que el nematodo puede replicarse en el huésped humano permitiendo ciclos de autoinfección que llevan a una enfermedad crónica, que puede durar décadas (4). Ésta infección crónica puede ser clínicamente inaparente o manifestarse por síntomas cutáneos, gastrointestinales o pulmonares $(1,5,6)$, pudiendo conllevar el fenó- meno denominado "hiperinfección" con incremento notable de parásitos fuera del tracto digestivo y que en el caso de pacientes inmunocomprometidos como infección por VIH (7), tumores malignos (8), transplantados(9) y sobre todo sometidos a terapia con cortisona (10) pueden evolucionar hacia la muerte.

La oportunidad de estudiar un paciente, residente siempre en Galicia, al que se objetivó eosinofilia periférica con datos sugestivos gastroenteropatía eosinófilica en la biopsia duodenal y al que, por tanto, estuvo a punto de administrársele cortisona y que resultó afecto de una infestación por Strongyloides stercoralis nos motiva a su publicación, siendo en nuestro conocimiento la primera vez que se documenta esta enfermedad en nuestra comunidad.

Trabajo aceptado: 14 de febrero de 2003

Correspondencia: C. Martínez-Vázquez. C/ Gran Vía, 3, 2º 36204 Vigo. 


\section{CASO APORTADO}

Varón de 25 años, natural y residente en Fornelos de Montes (Pontevedra). Negaba viajes fuera de su comunidad, trabajaba en una empresa de maderas y admitía haber trabajado ocasionalmente en labores agrícolas y bañarse en aguas de río.

Acudió a urgencias en el mes de Octubre remitido al objetivársele 22000 eosinófilos/ml en un hemograma solicitado por su médico de cabecera por presentar cuadro de dolor abdominal. Refería epigastralgia de 20 días de evolución que empeoraba con la ingesta junto con algún episodio diarreico y aparición de lesiones eritematopapulosas, alguna vesiculosa, con prurito en zona de muslos. Negaba fiebre u otra sintomatología.

A la exploración física se apreciaba un paciente con dolor a la palpación profunda en epigastrio y lesiones eritematopapulosas, alguna con vesículas, de un diámetro aproximado de $1-2 \mathrm{~cm}$., que fue valorado por Dermatología considerándose inespecíficas. El resto de la exploración por sistemas y aparatos fue rigurosamente normal.

En la analítica se apreció eosinofília absoluta de más de 20.000 elementos por $\mathrm{ml}$, con resto de hemograma normal. IgE116 KU/L (20-200), serología para VIH negativa, constantes de autoanalizador normales, cultivo de exudado de vesícula cutánea e inmunofluorescencia de virus herpes simple 1 y 2 negativos.

Tres muestras de heces fueron remitidas para investigación de parásitos. En la tercera muestra preservada con SAF (Sodium acetate-acetic acid-formalin) en el estudio en fresco con yodo y suero fisiológico con concentración con formol acetato de etilo se observó una larva de un tamaño aproximado de 340 Ìm, con una porción bucal corta, un amplio primordio genital y un extremo caudal afilado, todo ello compatible con una larva rabditiforme de Strongyloides spp (Figs 1a y 1b). No se observaron huevos ni quistes de ningún otro parásito. En seis cultivos posteriores, heces frescas (sin ningún tipo de conservante y sin refrigerar), son procesadas en agar-plate y agar-sangre, incubadas a $37^{\circ} \mathrm{C}$ y a temperatura ambiente (aproximadamente $22^{\circ} \mathrm{C}$ ) durante 48 horas. Después de lavar las placas con formaldehído al $10 \%$, dejando reposar 30 minutos y centrifugando 5 minutos a $500 \mathrm{~g}$ se pone de manifiesto la presencia de larvas filariformes de Strongyloides spp con la caracteristica morfología de su extremo caudal (Figs. 2a y 2b). El número de larvas encontradas fue superior utilizando agar-plate, aunque la diferencia no fue significativa. Se utilizó la técnica de Harada-Mori o técnica de cultivo en papel de filtro con agua destilada y tubo cónico, obteniéndose también cultivo positivo.

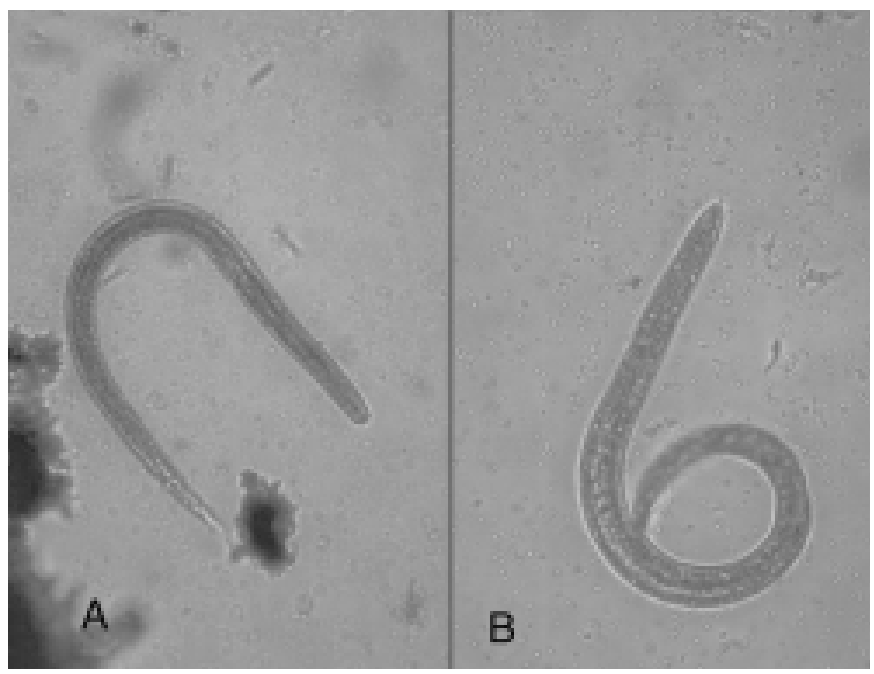

Figs. 1a-b. Larvas rabditiformes (ó del primer estadío) procedente de las heces del paciente. Tinción con yodo. Examen en fresco (x200).

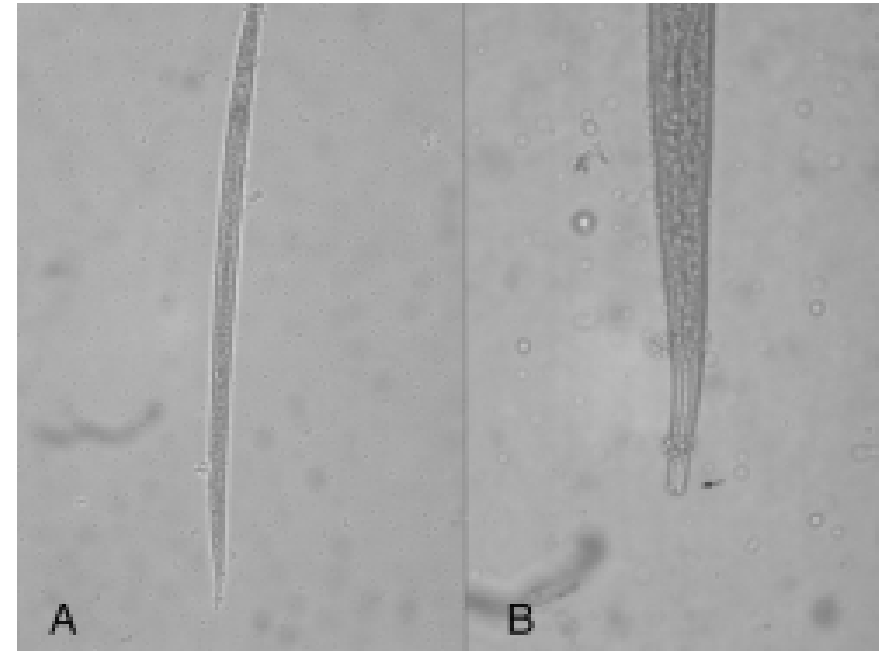

Fig. 2. a. Larva filariforme, infectiva ó del tercer estadío, recuperada de cultivo. Tinción con yodo. Examen en fresco $(\times 50) ; b$. Detalle del extremo caudal "ranurado" característico (x600).

A su vez la radiografía de tórax fue normal, documentándose en la TAC abdominal un engrosamiento difuso de la pared de yeyuno proximal. Se realizó gastroduodenoscopia en donde se apreció duodenitis aguda leve, evidenciándose en la biopsia duodenal un incremento de la población habitual de leucocitos eosinófilos en la lámina propia con extensión hacia el epitelio de superficie en algunos puntos, la mucosa gástrica no mostraba alteraciones. Este resultado se obtuvo antes del estudio definitivo de parásitos en heces, interpretándose como compatible con enteropatía eosinofílica. A posteriori no se apreciaron formas compatibles con parásitos en la muestra histopatológica procedente del duodeno.

El paciente recibió inicialmente tratamiento con albendazol 400mgr. al día durante 3 días. Con este fármaco desapareció la sintomatología de dolor abdominal, si bien un nuevo estudio de heces realizado cuatro semanas más tarde siguió demostrando la presencia de larvas de Strongyloides stercoralis, por lo que fue medicado con ivermectina 200mgr/kgr en una dosis con normalización de su cifra de eosinófilos y negativización de parásitos en heces. El paciente seis meses más tarde se encuentra asintomático y sin eosinofilia periférica.

\section{DISCUSIÓN}

Para entender la importancia de Strongyloides stercoralis como única infestación crónica es imprescindible conocer su ciclo biológico. La larva filariforme del Strongyloides stercoralis, también denominada $\mathrm{L} 3$ atraviesa la piel del ser humano alcanzando los pulmones a través de la circulación y posteriormente el intestino con la deglución. A este nivel madura convirtiéndose en hembra partenogenética (capaz de reproducirse por sí misma) quien coloca los huevos en la pared abdominal donde eclosionan internamente dando lugar a la larva de primer estadio, también llamada larva rabditiforme o L1, que pasa a las heces. Ya en el suelo se desarrolla directamente a segundo estadio L2 y tercer estadio L3 o larva filariforme que se convierten en adultos masculinos y femeninos quienes a su vez libremente pueden reproducirse produciendo L1 que pasan a L3 completándose el ciclo. Pero es que además en el intestino el estadio L1 puede convertirse en estadio L3, pudiendo la larva penetrar la mucosa intestinal alcanzando de nuevo los pulmones o intestino delgado, estableciendo así el ciclo de repetidas infecciones endógenas que conlleva a la 
infección crónica o autoinfección (13). Es en los pacientes con inmunocompromiso, fundamentalmente los sometidos a tratamiento corticoideo en donde esta autoinfección puede alcanzar niveles sistémicos masivos, tan altos que pongan en peligro la vida del paciente en el llamado "síndrome de hiperinfección" (14).

El diagnóstico se sospecha fundamentalmente ante la presencia de eosinofilia (13) como ocurrió en nuestro paciente, junto a un cuadro clínico que depende del momento migratorio de la larva (rash prurítico pápulo-macular, síndrome de Löffler-like, dolor epigástrico con diarrea ocasional) (15), confirmándose por la presencia de larvas en las heces o fluido duodenal (13). En nuestro caso realizamos cultivo parasitario al no existir datos epidemiológicos que apoyasen el diagnóstico, lo que nos permitió además desarrollar el estadio L3 o filariforme, con su característico extremo caudal ranurado lo que nos permitió excluir otros parásitos como Trichostrongilus spp. y Ancylostoma spp (12).

En cuanto al tratamiento destacamos como con albendazol aunque hubo una mejoría clínica importante no conseguimos la erradicación del parásito, algo que se consiguió con la ivermectina a dosis de $200 \mathrm{microgr} / \mathrm{Kg} / \mathrm{día}$, en una dosis, droga que recientemente han sido registrada como esencial para el tratamiento del Strongyloides sercoralis por la Organización Mundial de la Salud (16).

Por último queremos señalar que si no se hubiese documentado la presencia de Strongyloides sercoralis, ante los hallazgos de la biopsia intestinal, eosinofilia y clínica del paciente le hubiésemos diagnosticado de gastroenteritis eosinofílica (17-19), con lo que supondría de riesgo de "síndrome de hiperinfección" al administrársele, como es preceptivo en esta enfermedad, dosis altas y prolongadas de cortisona. Esto sin duda alguna hubiese puesto en peligro la vida del paciente añadiendo al resto de sintomatología parasitaria las bacteriemias causadas por el daño del epitelio intestinal (20).

Creemos por lo tanto que ante un cuadro como el de nuestro paciente, debemos aumentar nuestro índice de sospecha para la enfermedad por Strongyloides stercoralis aunque se haya residido siempre en zonas de España en las que hasta ahora no se haya documentado su existencia.

\section{Bibliografía}

1. Lin LX, Weller PF. Strongyloidiasis and other intestinal nematode infections. Infect Dis Clin North Am 1993; 7: 655-82.

2. Genta RM. Global prevalence of strongyloidiasis: Critical review with epidemiologic insights into the prevention of disseminated disease. Rev Infect Dis 1989; 11: 755-67.

3. Cremades MJ, Igual R, Ricard C, Estellés F, Pastor A, Menéndez R. Infección por Strongyloides stercoralis en la comarca de La Sabor (Comunidad Valenciana). Med Clin (Barc) 1997; 109: 212-5.

4. Grove D.I. Human strongyloidiasis. Adv Parasitol 1996;38:251309.

5. Berk SL, Verghese A, Álvarez S, Hall K, Smith B. Clinical and epidemiologic features of strongyloidiasis. A prospective study in rural Tennesee. Arch Intern Med 1987; 147: 1257-61.

6. Woodring JH, Halfhill H, Reed JC. Pulmonary strongyloidiasis: Clinical and imaging features. Am J Roentgenol 1994; 162: 537-42.

7. Heyworth MF. Parasitic diseases in immunocopromised host. Cryptosporodiosis, isosporiasis and strongyloidiasis. Gastroenterol Clin North Am 1996; 25: 691-707.

8. Rudrapatna JS, Kumar V, Sridhar H. Intestinal paracitic infections in patients with malignancy. J Diarrhoeal Dis Res 1997; 15: 71-4.

9. Palan LA, Pankey GA. Strongyloides hyperinfection en renal transplant recipient receiving cyclosporine: possible strongyloides stercoralis trasnmision by kidney transplant. Am J Trop Med Hyg 1997; 57: 413-5.

10. Igra-Siegman Y, Kapila R, Sen P, Kaminski ZC, Louria DB. Sybdrome

of hyperinfectionwith Strongyloides stercoralis. Rev Infect Dis 1981; 3: 397-407.

11. Arakaki TM, Iwanaga M, Kinjo F, Saito A, Asato R, Ikeshiro T. Efficacy of agar-plate culture in detection of Strogyloides stercoralis infection. J Parasitol 1990; 76: 425-8

12. Garcia LS, Brucker DA. Diagnostic Medical Parasitology. $3^{\text {a }}$ ed Washington: asm Press, 1997.

13. Siddiqui AA, Berk SL. Diagnosis of Strongyloides stercoralis infection. Clin Infect Dis 2001; 33: 1040-7.

14. Wehner JH, Kirsch CM. Pulmonary manifestations of strongyloidiasis. Semin Respir Infect 1997; 12: 122-9.

15. Mahmoud AAF. Strongyloidiasis. Clin Infect Dis 1996; 23: 949-52.

16. Albonico M. Crompton DW, Savioli L. Control strategies for human intestinal nematodo infections. Adv Parasitol 1999; 42: 277-341.

17. Tallex NJ, Shorter RG, Phillips SF, Zinsmeister AR. Eosinophilic gastroenteritis: A clinicopathological study of patiens with disease of the mucosa, muscle layer, and subserosal tissues. Gut 1990; 31: 54-8.

18. Eosinophilic gastroenteritis:10 years experience. Am J Gastroenterol 1993; 88: 70-3

19. Bischoff SC, Mayer J, Nguyen QT, Stolte M, Manns MP. Immunohitological assessment of intestinal eosinophil activation in patients with eosinophilic gastroenteritis and inflammatory bowel disease. Am J Gastroenterol 1999; 94: 3521-9.

20. Link K, Orenstein R. Bacterial complications of strongyloidiasis: Streptococcus bovis meningitis. South Med J 1999; 92: 728-31. 